\title{
Rare RET Variant p.D707E in a Chinese Pedigree with Hereditary Medullary Thyroid Carcinoma
}

\author{
Lu Zhang $^{\text {a }}$ Xiaoyu Li ${ }^{d}$ Qiyuan $\mathrm{Li}^{\text {b }}$ Shengxiang Ge ${ }^{\text {a }}$ Mengyuan Chen ${ }^{\text {a }}$ \\ Shuizhen Huang ${ }^{\mathrm{a}}$ Binbin Chen ${ }^{\mathrm{a}}$ Peng $\mathrm{Li}^{\mathrm{b}}$ Bogang Teng ${ }^{\mathrm{a}}$ Jing $\mathrm{Xu}^{\mathrm{c}}$ \\ Shupeng Zhao ${ }^{e}$ Fengjie $\mathrm{Qi}^{f}$ Yongxing Zhang ${ }^{\mathrm{a}}$
}


Medicine, Xiamen University, Xiamen, Departments of ${ }^{\mathrm{C}}$ Gynecology and ${ }^{\mathrm{d}}$ Otolaryngology-Head and Neck Surgery, The Affiliated Hospital of Jining Medical University, Jining, and Departments of ${ }^{\mathrm{e}}$ Thyroid and Breast Surgery and

fPathology, Luohu People's Hospital, Shenzhen, PR China

\section{Key Words}

Hereditary medullary thyroid carcinoma $\cdot$ RET

proto-oncogene $\cdot$ Variant $\cdot$ Single-nucleotide polymorphism

\begin{abstract}
Background: Hereditary medullary thyroid carcinoma (HMTC) is thought to be associated with germline mutations of the RET proto-oncogene. Methods: We detected RET proto-oncogene germline mutations from a pedigree with HMTC in the east of China and investigated the characteristics of these mutations in this pedigree and their correlation with HMTC by direct sequencing of all 21 exons in the RET gene of all 46 subjects. Results and Conclusion: (1) Thirteen types of RET gene variants were detected in this pedigree. Of these, p.F285S in exon 4, c.854_855CA in exon 4,
\end{abstract}

and p.D707E in exon 11 are reported for the first time in our study. (2) Both linkage disequilibrium analysis and logistic regression analysis showed a significant correlation between the p.D707E variant and HMTC (LOD = 3.69, OR = 4.413, $p=0.000167$ ), indicating that this variant is a risk factor for medullary thyroid carcinoma (MTC). (3) The single-nucleotide polymorphisms (SNP) G691S in exon 11 (rs1799939), S904S in exon 15 (rs1800863), and rs2075912 and rs2565200 in the $3^{\prime}$-untranslated region of the RET proto-oncogene are in complete linkage disequilibrium $\left(D^{\prime}=1\right.$, $\left.r^{2}=1\right)$; no correlation of these SNP and MTC was observed in this pedigree. (4) No hot-spot mutation of the RET protooncogene was detected in this pedigree. We drew the conclusion that the heterozygous nonsynonymous variant p.D707E in the RET proto-oncogene is rare, but it is a risk factor for hereditary MTC.
Lu Zhang and Xiaoyu Li are co-first authors.

\section{KARGER}

๑ 2016 S. Karger AG, Basel

E-Mail karger@karger.com

www.karger.com/pat
Prof. Yongxing Zhang

State Key Laboratory of Molecular Vaccinology and Molecular Diagnostics

School of Public Health, Xiamen University

Fujian, Xiamen 361102 (PR China)

E-Mail z63y94x@163.com

Prof. Fengjie Qi

Department of Pathology

Luohu People's Hospital, No. 47 Youyi Road

Shenzhen, Guandong 518001 (PR China)

E-Mail z63y94x@163.com 


\section{Introduction}

Medullary thyroid carcinoma (MTC) is a rare aggressive endocrine tumor that arises from parafollicular C cells that produce calcitonin, and it accounts for 5-10\% of all thyroid cancers. About $75 \%$ of all MTC are sporadic forms, while $25 \%$ are hereditary MTC (HMTC) [1-3]. HMTC is an autosomal dominant genetic disease with 3 subtypes: multiple endocrine neoplasia type $2 \mathrm{~A}$ (MEN 2A; 55-60\%), multiple endocrine neoplasia type 2B (MEN 2B; 5-10\%) and familial MTC (35-40\%). MEN 2A is generally accompanied by adrenal pheochromocytoma (PHEO) and/or hyperparathyroidism, and the onset age usually ranges from 20 to 30 years [3-5].

The pathogenesis of MTC is thought to be associated with mutations of the RET proto-oncogene (RET, OMIM.164761), which is mapped on chromosome 10q11.2 and contains 21 exons encoding a membrane tyrosine kinase receptor that mediates the processes of neural crest-derived cells, such as proliferation, differentiation, and migration. The probability of carriers with germline mutations of this gene to develop HMTC is about $90 \%$ [6-8]. Half of these patients' first-degree relatives seem to be at risk for carrying the mutated gene [9]. In the inherited cases about $98 \%$ of the patients harbor germline mutations in this gene, and in the sporadic cases approximately $45 \%$ of the patients carry somatic mutations [10-12]. HMTC is generally associated with RET proto-oncogene germline mutations, which are frequently distributed in hot-spot exons (i.e. 5, 8, 10, $11,13,14,15$, and 16) mainly affecting the 2 domains of RET: the extracellular cysteine-rich (ECR) region and the intracellular tyrosine-kinase (ITK) domain. Mutations in these 2 domains may result in changes in protein conformation in the extracellular domain and the intracellular domain, respectively. These changes in protein conformation could enhance the transforming ability of RET, automatically stimulating tyrosine kinase phosphorylation, inducing excessive cell hyperplasia, and eventually leading to a tumor. Therefore, these 2 domains play an important role in the development of MTC $[13,14]$.

Herein, we detect RET proto-oncogene germline mutations in a pedigree with HMTC to understand the characteristics of these mutations. RET gene screening could be essential for the prevention of MTC and to facilitate the proper clinical management of MTC patients.
Table 1. Primers used for PCR amplification

\begin{tabular}{|c|c|c|c|c|}
\hline Exon & $\mathrm{F} / \mathrm{R}$ & Primers $\left(5^{\prime}-3^{\prime}\right)$ & $\begin{array}{l}\text { Size, } \\
\text { bp }\end{array}$ & $\begin{array}{l}\text { Tempera- } \\
\text { ture, }{ }^{\circ} \mathrm{C}\end{array}$ \\
\hline \multirow[t]{2}{*}{1} & $1 \mathrm{~F}$ & TCTCTACTACCCCAGGATGC & 1,316 & 61.2 \\
\hline & $1 \mathrm{R}$ & CAGAACTCTCCGCACGAATC & & 65.1 \\
\hline \multirow[t]{2}{*}{2} & $2 \mathrm{~F}$ & TGTCCTTGAAGAAGCCTTAT & 400 & 59 \\
\hline & $2 \mathrm{R}$ & GTGTCAGCGGCTGTGATAAG & & 63.5 \\
\hline \multirow[t]{2}{*}{3} & $3 \mathrm{~F}$ & CCССACAGACCTGACTTCTC & 400 & 63.5 \\
\hline & $3 R$ & AACCAGATGGCTTGTGTCAA & & 63 \\
\hline \multirow[t]{2}{*}{4} & $4 \mathrm{~F}$ & CAAACTCGTAAGCACAGTCA & 439 & 58.8 \\
\hline & $4 \mathrm{R}$ & CTTCCGCTTGAACTCCACCA & & 68 \\
\hline \multirow[t]{2}{*}{5} & $5 \mathrm{~F}$ & ACGTGCAGCATTCTAAGGTC & 367 & 62.4 \\
\hline & $5 \mathrm{R}$ & TGTGTGTAGGGTGCTGCTTG & & 64.6 \\
\hline \multirow[t]{2}{*}{6} & $6 \mathrm{~F}$ & GTGTCTGGGAAGAGGTGTGC & 315 & 64.3 \\
\hline & $6 \mathrm{R}$ & TCAATCTTCCCCAGACAGGC & & 66.8 \\
\hline \multirow[t]{2}{*}{7} & $7 \mathrm{~F}$ & TTCCAGGACTTAGGCTGTGT & 503 & 61.7 \\
\hline & $7 \mathrm{R}$ & TTACTGCTGGGTCACTCAGG & & 62.8 \\
\hline \multirow[t]{2}{*}{8} & $8 \mathrm{~F}$ & GCTGGTGCTGTTCCCTGTCC & 446 & 69.6 \\
\hline & $8 \mathrm{R}$ & CCTTCCCAAGTCCAGAGTGA & & 64.2 \\
\hline \multirow[t]{2}{*}{9} & $9 \mathrm{~F}$ & TCCAGTTGCTCCTCCCTAGA & 239 & 64.3 \\
\hline & $9 \mathrm{R}$ & CCATGCCCTGATTAAACCCT & & 66.3 \\
\hline \multirow[t]{2}{*}{10} & $10 \mathrm{~F}$ & CACCCATGGCTTCAGAAAGG & 375 & 67.4 \\
\hline & $10 \mathrm{R}$ & TGTGCTGTTGAGACCTCTGT & & 60 \\
\hline \multirow[t]{2}{*}{11} & $11 \mathrm{~F}$ & CATGAGGCAGAGCATACGCA & 512 & 67.5 \\
\hline & $11 \mathrm{R}$ & CCCACAGACTGTCCCCACAC & & 67.3 \\
\hline \multirow[t]{2}{*}{12} & $12 \mathrm{~F}$ & TCCTCCССТGTCATCCTCAC & 305 & 66.2 \\
\hline & $12 \mathrm{R}$ & GCTCTTCAGGGTCCCATGCT & & 68.5 \\
\hline \multirow[t]{2}{*}{13} & $13 \mathrm{~F}$ & GTCTTTGCAGGCCTCTCTGT & 301 & 63.8 \\
\hline & $13 \mathrm{R}$ & GAGAACAGGGCTGTATGGAG & & 61.5 \\
\hline \multirow[t]{2}{*}{14} & $14 \mathrm{~F}$ & GCTGTGTCCACCCCCTTACT & 452 & 65.9 \\
\hline & $14 \mathrm{R}$ & TAGAGTGTGGCATGGTGGGG & & 68.3 \\
\hline \multirow[t]{2}{*}{15} & $15 \mathrm{~F}$ & TGGGCGACCTCATCTCATTT & 604 & 65.9 \\
\hline & $15 \mathrm{R}$ & CTAGGCTTCCCAAGGGCACT & & 66.3 \\
\hline \multirow[t]{2}{*}{16} & $16 \mathrm{~F}$ & GCCTGGCCTTCTCCTTTACC & 184 & 66.1 \\
\hline & $16 \mathrm{R}$ & GTAACСТCCACCCCAAGAGA & & 63.3 \\
\hline \multirow[t]{2}{*}{17} & $17 \mathrm{~F}$ & GACATCTGTGAGCATCTGTG & 328 & 57.6 \\
\hline & $17 \mathrm{R}$ & CACAGATGTCCССТCССТTC & & 65.9 \\
\hline \multirow[t]{2}{*}{18} & $18 \mathrm{~F}$ & GGCCCTGCTTGGATCATATT & 218 & 64.8 \\
\hline & $18 \mathrm{R}$ & AACTACTGCCCTGGGGTGAG & & 63.3 \\
\hline \multirow[t]{2}{*}{$19-1$} & $19-1 \mathrm{~F}$ & TCTAGTTGTGGCACATGGCT & 595 & 55.1 \\
\hline & $19-1 \mathrm{R}$ & GGCTCCTTTCTCAACTGAAT & & 58.5 \\
\hline \multirow[t]{2}{*}{$19-2$} & $19-2 \mathrm{~F}$ & AAATATACAAATCTGGGGAG & 502 & 56.1 \\
\hline & $19-2 \mathrm{R}$ & GGAACCGTCTCAGCTTGAAA & & 64.8 \\
\hline \multirow[t]{2}{*}{20} & $20 \mathrm{~F}$ & TCTAGTTGTGGCACATGGCT & 244 & 63.3 \\
\hline & $20 \mathrm{R}$ & CGGTGCTAGAATCTAGTAAA & & 55.1 \\
\hline \multirow[t]{2}{*}{$21-1$} & $21-1 \mathrm{~F}$ & GAGTTTTGCCAAGGCCTTAC & 825 & 64.1 \\
\hline & $21-1 \mathrm{R}$ & TCTCAAGATCTCGAATGCTG & & 60.4 \\
\hline $21-2$ & $21-2 \mathrm{~F}$ & GCCTGGGGGTAGTGTCAATG & 798 & 67.1 \\
\hline & $21-2 \mathrm{R}$ & GAGACTTCCCAAAAGCTGCC & & 66.1 \\
\hline $21-3$ & $21-3 \mathrm{~F}$ & TTGTCATTCTTCATTGCTTG & 986 & 58.8 \\
\hline & $21-3 R$ & ATGCCTCAGTGGTTATCATG & & 60 \\
\hline
\end{tabular}

$\mathrm{F}=$ Forward; $\mathrm{R}=$ reverse .
Rare RET Variant p.D707E in a Chinese Pedigree with HMTC
Pathobiology 2017;84:152-160 DOI: $10.1159 / 000448845$
153 


\section{Subjects and Methods}

All procedures followed were in accordance with the ethical standards of the responsible committee on human experimentation (institutional and national) and with the Helsinki Declaration of 1975 , as revised in 2000 .

A 5-generation Chinese Han pedigree with HMTC from Shandong Province, China, was investigated. All 46 subjects provided written informed consent for participation in this study, as required by the Medical Ethics Committee of the School of Public Health of Xiamen University.

Genomic DNA was isolated from EDTA anti-coagulated peripheral blood $(5 \mathrm{ml})$ of all subjects. Leukocytes were isolated using the standard salting out/proteinase $\mathrm{K}$ method, dissolved in $\mathrm{TE}$ buffer, and stored at $-20^{\circ} \mathrm{C}$.

All primers were designed using Oligo 6.0 software (NCBI reference sequence: NG_007489.1) and synthesized by Sangon Biotech (Shanghai, China) (table 1). Because exons 19 and 21 are too long, they were divided into 2 pairs of primers (i.e. 19-1 and 19-2) and 3 pairs of primers (i.e. 21-1, 21-2, and 21-3), respectively.

Polymerase chain reaction amplification was performed for all 21 exons in the RET gene, and the samples were then run on a $2 \%$ agarose gel. The polymerase chain reaction products were purified and sequenced using an ABI Prism 3130X automatic sequencer (Applied Biosystems, USA). The sequences were compared with

Table 2. Basic characteristics of the 46 subjects

\begin{tabular}{lllll}
\hline & $\begin{array}{l}\text { MTC } \\
\text { only }\end{array}$ & $\begin{array}{l}\text { MTC+ } \\
\text { PHEO }\end{array}$ & Normal & Total \\
\hline Females, n & 5 & 3 & 16 & 24 \\
Males, n & 3 & 2 & 17 & 22 \\
Female:male ratio & $1.67: 1$ & $1.50: 1$ & $0.94: 1$ & $1.09: 1$ \\
Age range, years & $26-83$ & $29-54$ & $3-70$ & $3-83$ \\
\hline
\end{tabular}

RET sequence data from the NCBI BLAST human database (http:// www.ncbi.nlm.nih.gov/BLAST/), the UCSC Genome Browser (http://genome.ucsc.edu/cgi-bin/hgBlat), and the ExAC Browser (http://exac.broadinstitute.org/), respectively.

\section{Statistical Analysis}

Linkage disequilibrium was analyzed using the $\mathrm{R}$ package paramlink. LOD scores $>3$ indicated a linkage between the variant and the disease. LOD scores $\leq 2$ indicated no linkage between the variant and the disease. SPSS 17.0 (SPSS Inc., Chicago, Ill., USA) was used for logistic regression analysis to determine whether these 13 types of variants are risk factors for HMTC.

\section{Results}

\section{Basic Characteristics of the Subjects}

A total of 46 participants were included in this study (24 females and 22 males, female:male ratio: 1.09:1, age range: $3-83$ years). Of these, 8 patients (age range: $26-83$ years) had MTC alone, 5 patients (age range: $29-54$ years) had MTC accompanied by PHEO, and the remaining 33 patients were the unaffected relatives of these patients. The basic characteristics of the 46 subjects are listed in table 2. Information about the phenotype, the age at the onset of MTC and PHEO, and the age at surgery for MTC and PHEO is listed in table 3. The age at the onset of MTC ranged from 18 to 50 years, and family members III- 5 and III-18 presented recurrence of MTC after surgical treatment for the first time. The age at the onset of PHEO ranged from 26 to 50 years. We provide a representative sample of histology images of tumor tissue from a patient with HMTC in this pedigree. The results of hematoxylin-

Table 3. Basic characteristics of the 13 patients

\begin{tabular}{llllcccc}
\hline Subject & Gender & $\begin{array}{l}\text { Age, } \\
\text { years }\end{array}$ & Phenotype & $\begin{array}{l}\text { Age at onset } \\
\text { of MTC, years }\end{array}$ & $\begin{array}{l}\text { Age at surgery } \\
\text { for MTC, years }\end{array}$ & $\begin{array}{l}\text { Age at onset } \\
\text { of PHEO, years }\end{array}$ & $\begin{array}{l}\text { Age at surgery } \\
\text { for PHEO, years }\end{array}$ \\
\hline III-2 & F & 52 & MTC+PHEO & 18 & 18 & 37 (bilateral) \\
III-3 & M & 83 & MTC only & - & - & 42 \\
III-5 & M & 71 & MTC only & 46 & 46 and 50 & \\
III-8 & F & 48 & MTC only & - & - & 47 \\
III-11 & M & 48 & MTC+PHEO & 45 & 51 & 46 (bilateral) \\
III-14 & F & 54 & MTC+PHEO & 50 & 33 and 62 & 47 \\
III-18 & F & 65 & MTC only & 33 & 47 & 48 (left) \\
III-19 & M & 50 & MTC+PHEO & 47 & - & 26 (bilateral) \\
III-25 & M & 54 & MTC only & - & 26 & 48 \\
IV-2 & F & 29 & MTC+PHEO & 26 & - & 26 \\
IV-3 & F & 26 & MTC only & - & 23 & \\
IV-5 & F & 27 & MTC only & 23 & 25 & \\
IV-15 & F & 28 & MTC only & 18 & & 48 \\
\hline
\end{tabular}

- = Lack of information; $\mathrm{M}=$ male; $\mathrm{F}=$ female. 
eosin (HE) staining and immunohistochemical staining [calcitonin (CT), chromogranin A (CgA), synaptophysin (Syn), carcinoembryonic antigen (CEA), S100, and thyroglobulin (TG)] were in accordance with the diagnosis of MTC. Tumor cells in HE staining were round, polygonal, and spindle shaped, and the nucleus was lightly stained; the ratio of nucleus to cytoplasm was low, and the tumor cells were arranged in nests, with pink dense amyloids around the cells. Staining for CT, CgA, CEA, and Syn showed a positive expression in the cytoplasm of tumor cells and a negative expression in thyroid follicular epithelial cells. TG showed a negative expression in tumor cells, while its expression in the thyroid follicular epithelial cytoplasm was strongly positive. Immunohisto-

Fig. 1. Immunohistochemical staining of a representative HMTC patient in this pedigree. HE. $\times 100$. The tumor cells are arranged in nests, with pink dense amyloids around the cells. The expressions of CT, CgA, Syn, and CEA are positive $(\times 200)$. The expressions of $\mathrm{S} 100$ and TG are negative in tumor cells $(\times 100)$.


Rare RET Variant p.D707E in a Chinese

Pathobiology 2017;84:152-160 
Table 4. Distribution of the 13 types of variants in the RET gene

\begin{tabular}{|c|c|c|c|c|c|c|c|c|c|c|c|}
\hline Region & Position & SNP ID & RET mutation & $\begin{array}{l}\text { Total, } \\
\mathrm{n}\end{array}$ & $\begin{array}{l}\text { Female to } \\
\text { male ratio }\end{array}$ & $\begin{array}{l}\text { Patient } \\
\text { to normal } \\
\text { subject } \\
\text { ratio }\end{array}$ & $\begin{array}{l}\text { Homozygous } \\
\text { to hetetero- } \\
\text { zygous ratio }\end{array}$ & $\begin{array}{l}\text { LOD } \\
\text { score } \\
\text { (MTC) }\end{array}$ & $\mathrm{p}$ & $\begin{array}{l}\text { LOD } \\
\text { score } \\
(\mathrm{PHEO})\end{array}$ & $\mathrm{p}$ \\
\hline Exon 2 & 43595968 & rs1800858 & p.A45A & 45 & $23: 22$ & $13: 32$ & $42: 3$ & NA & 0.995 & NA & 0.995 \\
\hline Exon 4 & 43600628 & - & p.F285S & 7 & $3: 4$ & $1: 6$ & $7: 0$ & NA & 0.451 & NA & 0.575 \\
\hline Exon 4 & $\begin{array}{l}43600628- \\
43600629\end{array}$ & - & C.854_855CA & 9 & $6: 3$ & $3: 6$ & $9: 0$ & NA & 0.583 & NA & 0.137 \\
\hline Exon 7 & 43606687 & rs 1800860 & p.A432A & 45 & $23: 22$ & $13: 32$ & $27: 18$ & 0.22 & NA & 0.00 & NA \\
\hline Exon 11 & 43610119 & rs1799939 & p.G691S & 1 & $1: 0$ & $0: 1$ & $1: 0$ & NA & 0.995 & NA & 0.995 \\
\hline Exon 11 & 43610169 & - & p.D707E & 15 & $8: 7$ & $11: 4$ & $15: 0$ & $3.69^{\mathrm{a}}$ & 0.0002 & 0.39 & 0.995 \\
\hline Exon 13 & 43613843 & rs1800861 & p.L769L & 23 & $13: 10$ & $4: 19$ & $0: 23$ & 0.28 & 0.186 & 0.00 & 1.000 \\
\hline Exon 13 & 43613868 & rs75686697 & p.V778I & 7 & $6: 1$ & $0: 7$ & $0: 7$ & 0.70 & 0.994 & 0.00 & 0.995 \\
\hline Exon 15 & 43615633 & rs1800863 & p.S904S & 13 & $9: 4$ & $1: 12$ & $0: 13$ & 0.22 & 0.105 & 0.00 & 0.995 \\
\hline 3'-UTR & 43622217 & rs2075912 & C. ${ }^{*} 15 \mathrm{~T}>\mathrm{C}$ & 44 & $23: 21$ & $13: 31$ & $22: 22$ & & & & \\
\hline $3^{\prime}$-UTR & 43622369 & rs2075913 & C. ${ }^{*} 167 \mathrm{~T}>\mathrm{A}$ & 37 & $19: 18$ & $8: 29$ & $12: 25$ & & & & \\
\hline $3^{\prime}$-UTR & 43622933 & rs2565200 & C. ${ }^{*} 731 \mathrm{~T}>\mathrm{C}$ & 43 & $22: 21$ & $13: 30$ & $21: 22$ & & & & \\
\hline $3^{\prime}$-UTR & 43625223 & rs2742241 & C. ${ }^{*} 1506 \mathrm{G}>\mathrm{A}$ & 39 & $21: 18$ & $11: 28$ & $17: 22$ & & & & \\
\hline
\end{tabular}

- = No related information was found in the NCBI BLAST human database, the UCSC Genome Browser, or the ExAC Browser; $\mathrm{NA}=$ not applicable; $\mathrm{p}=$ probability from the logistic regression analysis. ${ }^{\mathrm{a}} \mathrm{LOD}$ scores $>3$ were considered to determine a linkage between the variant and the disease.

chemical staining of $\mathrm{S} 100$ presented a negative expression in both tumor cells and thyroid follicular epithelial cells (fig. 1). The HMTC cases found in our study did not have distinct histologic features compared to MTC tumors with other types of RET mutations.

\section{RET Proto-Oncogene Germline Mutation Detection and Variation Annotation}

The results of mutation detection showed 13 types of germline variants in the 21 exons of the RET proto-oncogene. They were: p.A45A in exon 2, p.F285S and c.854_855CA in exon 4, p.A432A in exon 7, p.D707E and p.G691S in exon 11, p.L769L and p.V778I in exon 13, p.S904S in exon 15 , and c. ${ }^{*} 15 \mathrm{~T}>\mathrm{C}, \mathrm{c} .{ }^{*} 167 \mathrm{~T}>\mathrm{A}, \mathrm{c} .{ }^{*} 731 \mathrm{~T}>\mathrm{C}$, and c. ${ }^{*} 1506 \mathrm{G}>\mathrm{A}$ in the $3^{\prime}$-untranslated region ( $3^{\prime}$-UTR). Among the 13 variants, no information on p.F285S and c.854_855CA in exon 4 or p.D707E in exon 11 was found in the NCBI, UCSC, and ExAC databases, suggesting that these 3 variants have not yet been reported. Of the remaining 10 variants, single-nucleotide polymorphisms (SNP) such as p.A45A, p.A432A, p.G691S, and p.L769L were confirmed to be related to C-cell hyperplasia, sporadic MTC, papillary thyroid carcinoma, and Hirschsprung's disease in some populations [5, 15-18]. However, no correlation was found between these variants and $\mathrm{MTC} / \mathrm{PHEO}$ in this pedigree.
Among the 13 types of variants in this pedigree, patients with MTC alone and those with MTC accompanied by PHEO carried 11 types of variants, while the other 2 variants, i.e. p.G691S and p.V778I, were not found in any of the MTC patients. We analyzed the prevalence of the 11 variants of mutation carriers. Among these, the prevalence of p.D707E mutation carriers was highest (i.e. 73.33\%; 11/15) (table 5).

Familial MTC pedigrees harbor hot-spot mutations such as codons $609,611,618$, and 620 in exon 10 and codon 634 in exon 11 (the most frequent mutation) in the ECR region of the RET gene [5, 8]. Nevertheless, none of these mutations was detected in this pedigree.

\section{Linkage Disequilibrium Analysis}

In order to analyze the correlation of variants in the RET gene with the morbidity of MTC/PHEO, we conducted a linkage analysis of the 13 variants in the RET gene and MTC/PHEO using the R package paramlink (table 4). Among the 13 variants, only the heterozygous nonsynonymous variant p.D707E in exon 11 showed a significant correlation with MTC $(\mathrm{LOD}=3.69)$ (table 4). Meanwhile, logistic regression analysis indicated that p.D707E may be a risk factor for MTC $(\mathrm{OR}=4.413$, $\mathrm{p}=0.000167)$. Among the 46 family members of this pedigree, 15 carried the p.D707E variant, 11 had MTC (in-
156

Pathobiology 2017;84:152-160 DOI: $10.1159 / 000448845$
Zhang/Li/Li/Ge/Chen/Huang/Chen/Li/ Teng/Xu/Zhao/Qi/Zhang 


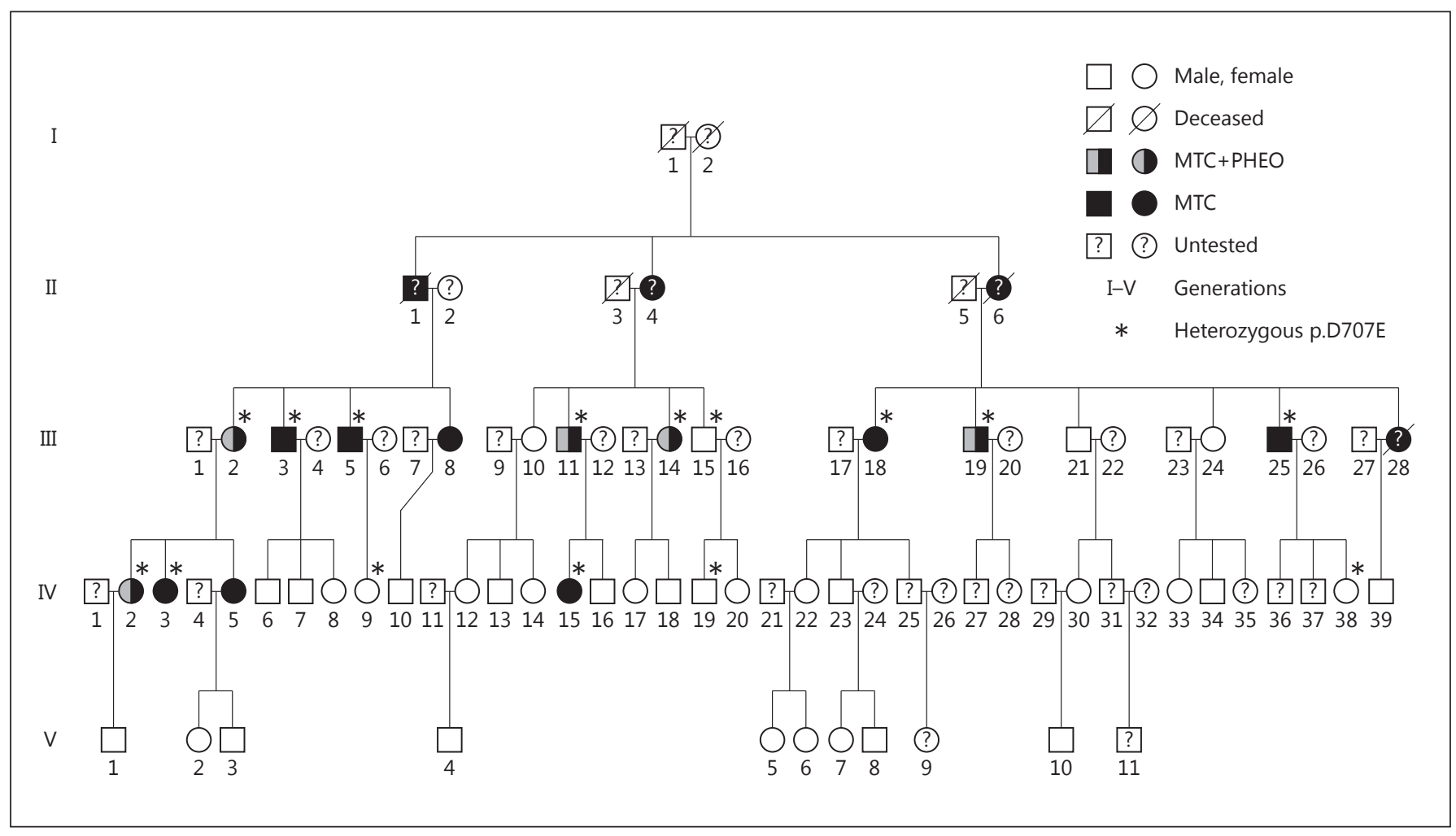

Fig. 2. Pedigree of the MTC/PHEO patients and their unaffected relatives. Fifteen family members carried the p.D707E variant in the heterozygous form, as indicated by the asterisks. Subjects III-3, III-5, III-18, III-25, IV-3, and IV-15 suffered from MTC alone, and subjects III-2, III-11, III-14, III-19, and IV-2 had MTC accompanied by PHEO; subjects III-15, IV-9, IV-19, and IV-38 were their unaffected relatives.

cluding 6 with MTC alone and 5 with MTC accompanied by PHEO), and the remaining 4 were their unaffected relatives. The distribution of this variant in this pedigree is shown in figure 2 , and the nucleotide change in this point mutation is shown in figure 3 . However, both the linkage disequilibrium analysis and the logistic regression analysis showed that p.D707E was irrelevant to PHEO (LOD = $0.386, \mathrm{OR}=19.55, \mathrm{p}=0.995$ ).

The results of the linkage analysis (HaploView 4.2 software) of all of the SNP in the RET proto-oncogene in the Chinese Han population (from the International HapMap Project) showed that 5 SNP [i.e. p.A432A (rs1800860), p.G691S (rs1799939), p.S904S (rs1800863), c. ${ }^{*} 15 \mathrm{~T}>\mathrm{C}(\mathrm{rs} 2075912)$, and c. $\left.{ }^{*} 731 \mathrm{~T}>\mathrm{C}(\mathrm{rs} 2565200)\right] \mathrm{de}-$ tected in this pedigree were linked to each other (fig. 4). Of these, SNP G691S in exon 11 and SNP S904S in exon $15\left(D^{\prime}=1.0, r^{2}=1.0, \mathrm{LOD}=12.83\right)$, and $\mathrm{rs} 2075912$ and rs $2565200\left(D^{\prime}=1.0, r^{2}=1.0, \mathrm{LOD}=20.23\right)$ in the $3^{\prime}$ UTR, were in complete linkage disequilibrium, which is consistent with the results of Sheikholeslami et al. [19].
Table 5. Prevalence of the 11 variants of mutation carriers

\begin{tabular}{|c|c|c|c|c|c|}
\hline Variant & $\begin{array}{l}\text { MTC } \\
\text { only }\end{array}$ & $\begin{array}{l}\text { MTC+ } \\
\text { PHEO }\end{array}$ & $\begin{array}{l}\text { Un- } \\
\text { affected }\end{array}$ & Total & Prevalence, $\%$ \\
\hline p.A45A & 8 & 5 & 32 & 45 & $28.89(13 / 45)$ \\
\hline p.F285S & 0 & 1 & 6 & 7 & $14.29(1 / 7)$ \\
\hline C.854_855CA & 1 & 2 & 6 & 9 & $33.33(3 / 9)$ \\
\hline p.A432A & 9 & 4 & 32 & 45 & $28.89(13 / 45)$ \\
\hline p.D707E & 6 & 5 & 4 & 15 & $73.33(11 / 15)$ \\
\hline p.L769L & 2 & 2 & 19 & 23 & $17.39(4 / 23)$ \\
\hline p.S904S & 1 & 0 & 12 & 13 & $7.69(1 / 13)$ \\
\hline C. ${ }^{*} 15 \mathrm{~T}>\mathrm{C}$ & 8 & 5 & 31 & 44 & $29.55(13 / 44)$ \\
\hline C. ${ }^{*} 167 \mathrm{~T}>\mathrm{A}$ & 5 & 3 & 29 & 37 & $21.62(8 / 37)$ \\
\hline C. ${ }^{*} 731 \mathrm{~T}>\mathrm{C}$ & 8 & 5 & 30 & 43 & $30.23(13 / 43)$ \\
\hline C. ${ }^{*} 1506 \mathrm{G}>\mathrm{A}$ & 6 & 5 & 28 & 39 & $28.21(11 / 39)$ \\
\hline
\end{tabular}

In an individual in this pedigree, the former 2 SNP (IV8 in fig. 2, unaffected relative) coexisted, and the latter 2 SNP coexisted in 41 individuals, including all 13 patients. 


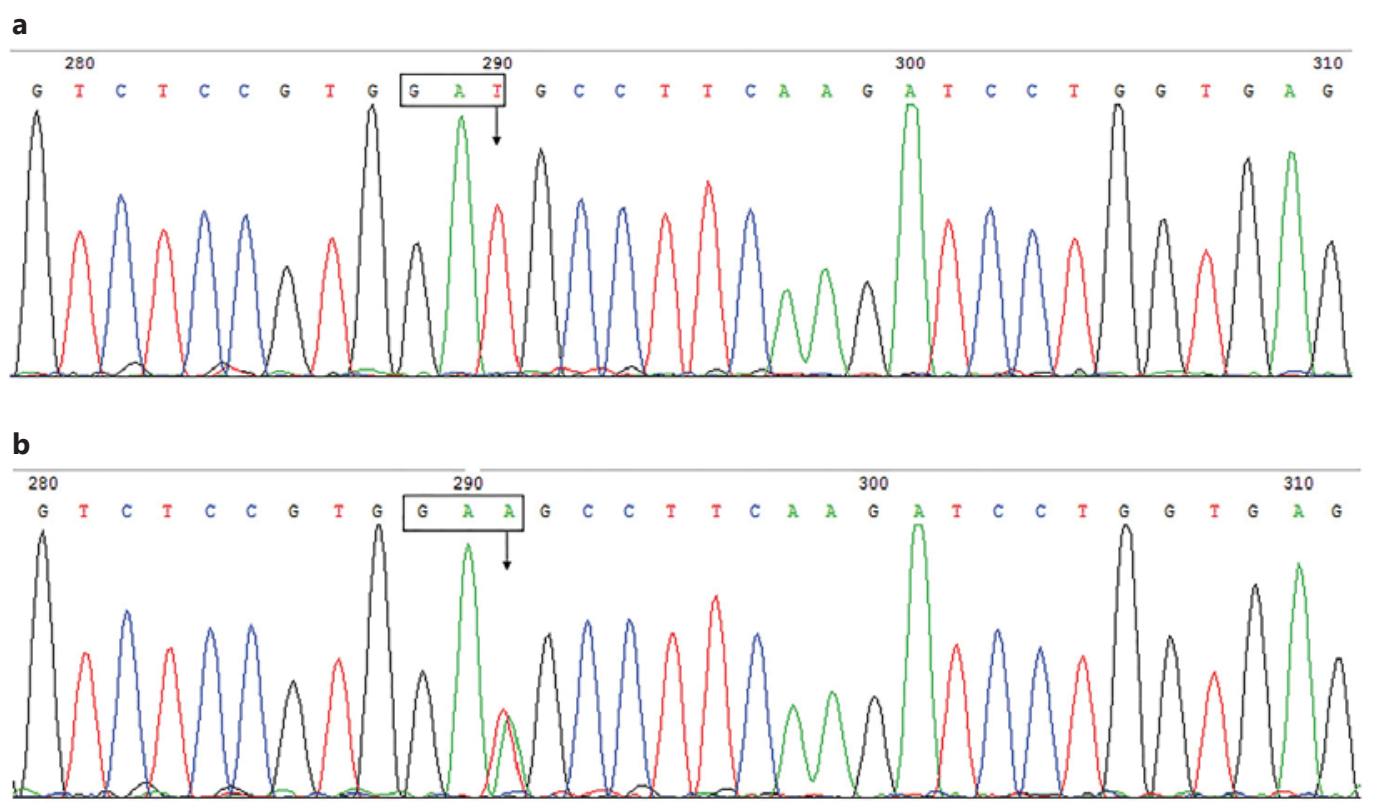

Fig. 3. Heterozygous aspartic acid-to-glutamate amino acid substitution within exon 11 of the RET gene. Missense c.T2121A (p.D707E) mutation in an MTC patient. The nucleotide change is indicated by the arrows. a Wild type. b Mutant c.T2121A p.D707E.

Fig. 4. LD plot indicating 5 SNP [i.e. p.A432A (rs1800860), p.G691S (rs1799939), p.S904S (rs1800863), c. ${ }^{*} 15 \mathrm{~T}>\mathrm{C}$ (rs2075912), and c. ${ }^{*} 731 \mathrm{~T}>\mathrm{C}$ (rs2565200)] in this pedigree which are linked to each other. The colors from light to dark (white to black) represent the level of linkage disequilibrium (low to high). The numbers in the blocks represent the strength of the association among the SNP, and black blocks indicate complete linkage disequilibrium. SNP in all of the positions are in linkage, and among these rs1799939 and rs1800863, as well as rs2075912 and rs2565200, are in complete linkage disequilibrium $\left(\left|D^{\prime}\right|=1, r^{2}=1\right)$.



\section{Discussion}

HMTC is a rare monogenic autosomal dominant genetic disease, the occurrence and development of which are related to germline mutations of the RET proto-oncogene [20]. Approximately $90 \%$ of pedigrees with MEN $2 \mathrm{~A}$ and familial MTC carry missense mutations in the ECR region cysteine conservative residue (codons 609, 611, 618, and 620 in exon 10 and codons 630 and 634 in exon
11) called hot-spot mutations. These mutations change the protein conformation in the extracellular region, which enhances the transforming capacities of RET, activates tyrosine kinase autophosphorylation, induces cell hyperplasia, and results in various endocrine tumors, including MTC $[3,5]$. However, the 13 types of variants of the RET gene that we detected in this pedigree did not have the above hot-spot mutations; of these, p.D707E in exon 11 and p.F285S and c.854_855CA in exon 4 have not 
yet been reported, p.D707E in exon 11 might be a risk factor for MTC, and the position of D707 in RET is located in the juxtamembrane region adjacent to the cytoplasmic domain. Bordeaux et al. [21] described RET as a new dependence receptor. It induces apoptosis in the absence of ligand, and the addition of GDNF is then sufficient to block RET proapoptotic activity [21]. The intracellular domain of RET was cleaved by caspase-3, generating 3 main cleavage products (i.e. 42,40 and $36 \mathrm{kDa}$ ) of RET in positions D707 and D1017, inducing apoptosis. Both the $\mathrm{D} 707 \mathrm{~N}$ and the $\mathrm{D} 1017 \mathrm{~N}$ point mutations failed to induce cell death. Therefore, we speculate that the mutation D707E detected in this pedigree suppressed RET proapoptosis activity, and caspase- 3 could not cleave RET in position D707, resulting in the block of RET-induced cell death. Taken together, this may be involved in the pathogenesis of the endocrine tumors developed in the patients described in our study.

Exons 11 and 13 are important functional regions of the RET gene $[3,10,22,23]$. Among the 13 variants in this pedigree, except p.D707E, p.G691S in exon 11, and p.L769L and p.V778I in exon 13 are located in the region that also codes ITK. Although statistical analysis showed no correlation between these variants and MTC, the possibility cannot be ruled out.

Since there are no reports of the D707E variant in the RET gene, we could not analyze the correlation between D707E and other SNP in the RET gene in this pedigree via linkage disequilibrium analysis. Eleven individuals carried the D707E variant in this pedigree and had MTC, and hence D707E mutation carriers are at a greater risk for MTC (11/15). There was no correlation between the other variants and MTC in these 11 patients by linkage disequilibrium analysis or logistic regression analysis. Therefore, we speculate that the D707E variant in the RET gene could be solely responsible for the development of MTC. Whether D707E is linked to other SNP in the RET proto-oncogene needs further study.

Kjaer and Ibáñez [24] and Castellone et al. [25] reported that the V292M variant was located in the third cadherinlike domain of the RET gene, and that this structure played a role in the RET gene through its ligand and variants of the structural domain facilitated the activation of the ligand-dependent RET gene. The carcinogenic potential of V292M is weaker than that of C634R and V804M [24, 25]. The newly identified homozygous variants p.F285S and c.854_855CA detected in this pedigree were located in the cadherin-like domain of the RET proto-oncogene, which is closer to V292M. Whether these 2 variants play a role similar to that of V292M needs further study.

Rare RET Variant p.D707E in a Chinese

Pedigree with HMTC
Linkage disequilibrium analysis of the correlation of 5 of the 13 SNP in the RET gene showed that SNP G691S in exon 11 (rs1799939) and SNP S904S in exon 15 (rs1800863) were in complete linkage disequilibrium, which is consistent with a previous report [23]. SNP G691S and S904S are associated with the development of MTC in patients who carry germline mutations of the RET gene [26-29]. They appear to influence the onset of HMTC, and the age at diagnosis of MTC in these homozygous pleomorphic patients is 10 years earlier than that for heterozygous MEN 2A or patients with the wild-type haplotype [30,31]. However, linkage analysis in this pedigree showed no linkage of SNP G691S and S904S with MTC, which is contrary to the above reports. This may be due to the coexistence of SNP G691S and SNP S904S in only one individual in this pedigree (IV-8 in fig. 2), i.e. a 29-year-old female without MTC at the time of reporting. As a consequence, we are unable to confirm whether individuals in whom SNP G691S and SNP S904S coexist in this pedigree would influence the onset of HMTC.

Whether the highly linked rs2075912 and rs2565200 in the $3^{\prime}$-UTR of the RET gene are associated with MTC needs further study.

The 13 variants of the RET gene in this pedigree are different from the hot-spot mutations that were reported in other pedigrees, especially the vital variant D707E. Screening of these 13 variants in this pedigree may provide the basis for the prevention of HMTC and play an instructive role in the clinical management of patients with MTC.

\section{Acknowledgements}

This study was financially supported by a grant from the Shandong Provincial Medical and Health Science and Technology Development Plan (2014WS0197).

\section{Author Contributions}

Lu Zhang, Xiaoyu Li, Shengxiang Ge, Fengjie Qi, and Yongxing Zhang contributed pertinent aspects of the planning. Mengyuan Chen, Shuizhen Huang, Shupeng Zhao, and Binbin Chen contributed pertinent aspects of the conduct. Peng Li, Bogang Teng, Jing $\mathrm{Xu}$, Qiyuan Li, and Yongxing Zhang contributed pertinent aspects of the report.

\section{Disclosure Statement}

Lu Zhang, Xiaoyu Li, Shengxiang Ge, Fengjie QI, Mengyuan Chen, Shuizhen Huang, Shupeng Zhao, Binbin Chen, Peng Li, Bogang Teng, Jing Xu, Qiyuan Li, and Yongxing Zhang declare that they have no conflicts of interest.

Pathobiology 2017;84:152-160

DOI: $10.1159 / 000448845$ 


\section{References}

1 Zhang Y, Wang S, Chen X, Huang S, Li, J: Quantitative assessment of the association between L769L and S836S polymorphisms at RET gene and medullary thyroid carcinoma risk. Tumour Biol 2014;35:6641-6647.

2 American Thyroid Association Guidelines Task Force, Kloos RT, Eng C, Evans DB, Francis GL, Gagel RF, Gharib H, Moley JF, Pacini F, Ringel MD, Schlumberger M, Wells SA Jr: Medullary thyroid cancer: management guidelines of the American Thyroid Association. Thyroid 2009;19:565-612.

3 Yeganeh MZ, Sheikholeslami S, Hedayati M: RET proto oncogene mutation detection and medullary thyroid carcinoma prevention. Asian Pac J Cancer Prev 2015;16:2107-2117.

4 Yeganeh MZ, Sheikholeslami S, Behbahani GD, Farashi S, Hedayati M: Skewed mutational spectrum of RET proto-oncogene Exon10 in Iranian patients with medullary thyroid carcinoma. Tumour Biol 2015;36: 5225-5231.

5 Chang CF, Yang WS, Su YN, Wu IL, Chang TC: Mutational spectrum of multiple endocrine neoplasia type 2 and sporadic medullary thyroid carcinoma in Taiwan. J Formos Med Assoc 2009;108:402-408.

6 Farndon JR, Leight GS, Dilley WG, Baylin SB, Smallridge RC, Harrison TS, Wells SA: Familial medullary thyroid carcinoma without associated endocrinopathies: a distinct clinical entity. Br J Surg 1986;73:278-281.

7 Eng C, Clayton D, Schuffenecker I, Lenoir G, Cote G, Gagel RF, van Amstel HKP, Lips CJM, Nishisho I, Takai SI, Marsh DJ, Robinson BG, Frank-Raue K, Raue F, Xue FY, Noll WW, Romei C, Pacini F, Fink M, Niederle B, Zedenius J, Nordenskjold M, Komminoth P, Hendy GN, Gharib H, Thibodeau SN, Lacroix A, Frilling A, Ponder BAJ, Mulligan LM: The relationship between specific RET proto-oncogene mutations and disease phenotype in multiple endocrine neoplasia type 2 - International RET Mutation Consortium analysis. JAMA 1996;276:1575-1579.

8 Pacini F, Castagna MG, Cipri C, Schlumberger M: Medullary thyroid carcinoma. Clin Oncol 2010;22:475-485.

9 Masby MH, Mohammadiasl Javad, Galehdari $\mathrm{H}$, Ahmadzadeh A, Tabatabaiefar MA, Golchin N, Haghpanah V, Rahim F: Characterization of wild-type and mutated RET protooncogene associated with familial medullary thyroid cancer. Asian Pac J Cancer Prev 2014; 15:2027-2033.

10 Raue F, Frank-Raue K: Update multiple endocrine neoplasia type 2. Fam Cancer 2010;9: 449-457.
11 Romei C, Elisei R, Pinchera A, Ceccherini I, Molinaro E, Mancusi F, Martino E, Romeo G, Pacini F: Somatic mutations of the ret protooncogene in sporadic medullary thyroid carcinoma are not restricted to exon 16 and are associated with tumor recurrence. J Clin Endocrinol Metab 1996;81:1619-1622.

12 Cordella D, Muzza M, Alberti L, Colombo P, Travaglini P, Beck-Peccoz P, Fugazzola L, Persani L: An in-frame complex germline mutation in the juxtamembrane intracellular domain causing RET activation in familial medullary thyroid carcinoma. Endocr Relat Cancer 2006; 13:945-953.

13 Pachnis V, Mankoo B, Costantini F: Expression of the c-ret proto-oncogene during mouse embryogenesis. Development 1993; 119:1005-1017.

14 Silva AL, Carmo F, Moura MM, Domingues R, Espadinha C, Leite V, Cavaco B, Bugalho MJ: Identification and characterization of two novel germline RET variants associated with medullary thyroid carcinoma. Endocrine 2015;49:366-372.

15 Guido F, Mandy S, Eberhard K, Matthias S, Andreas Z, Dietmar R, Schackert HK: Novel intronic polymorphisms in the RET protooncogene and their association with Hirschsprung disease. Hum Mutat 2003;22:177-177.

16 Sangkhathat S, Kusafuka T, Chengkriwate P, Patrapinyokul S, Sangthong B, Fukuzawa M: Mutations and polymorphisms of Hirschsprung disease candidate genes in Thai patients. J Hum Genet 2006;51:1126-1132.

17 Figlioli G, Landi S, Romei C, Elisei R, Gemignani F: Medullary thyroid carcinoma (MTC) and RET proto-oncogene: mutation spectrum in the familial cases and a meta-analysis of studies on the sporadic form. Mutat Res 2013;752:36-44.

18 Lantieri F, Caroli F, Ceccherini I, Griseri P. The involvement of the RET variant G691S in medullary thyroid carcinoma enlightened by a meta-analysis study. Int J Cancer 2013;132: 2808-2819.

19 Sheikholeslami S, Yeganeh MZ, Rad LH, Ghadaksaz HG, Hedayati M: Haplotype frequency of G691S/S904S in the RET proto-oncogene in patients with medullary thyroid carcinoma. Iranian J Public Health 2014;43: 235-240.

20 Frilling A, Dralle H, Eng C, Raue F, Broelsch CE: Presymptomatic DNA screening in families with multiple endocrine neoplasia type 2 and familial medullary thyroid carcinoma. Surgery 1995;118:1099-1104.

21 Bordeaux MC, Forcet C, Granger L, Corset V, Bidaud C, Billaud M, Bredesen DE, Edery P, Mehlen P: The RET proto-oncogene induces apoptosis: a novel mechanism for Hirschsprung disease. EMBO J 2000;19:4056-4063.
22 Segouffin-Cariou C, Billaud M: Transforming ability of MEN2A-RET requires activation of the phosphatidylinositol 3-kinase/AKT signaling pathway. J Biol Chem 2000;275:35683576.

23 Hedayati M, Zarif YM, Sheikhol ES, Rezghi BS, Hoghooghi RL, Azizi F: Predominant RET Germline Mutations in Exons 10, 11, and 16 in Iranian Patients with Hereditary Medullary Thyroid Carcinoma. J Thyroid Res 2011; 2011:264248.

24 Kjaer S, Ibáñez CF: Identification of a surface for binding to the GDNF-GFR alpha $1 \mathrm{com}$ plex in the first cadherin-like domain of RET. J Biol Chem 2003;278:47898-47904.

25 Castellone MD, Verrienti A, Rao DM, Sponziello M, Fabbro D, Muthu M, Durante C, Maranghi M, Damante G, Pizzolitto S: A novel de novo germ-line V292M mutation in the extracellular region of RET in a patient with phaeochromocytoma and medullary thyroid carcinoma: functional characterization. Clin Endocrinol 2010;73:529-534.

26 Arancha C, Fabienne L, Sam M, Jean L, Shahana A, Craig L, Smith PL, Robert L, Joanne W, Pharoah PD: Polymorphisms in the initiators of RET (rearranged during transfection) signaling pathway and susceptibility to sporadic medullary thyroid carcinoma. J Clin Endocrinol Metab 2005;90:6268-6274.

27 Mercedes R, Laura G, Marina P, Arancha C, Sergio R, Marta AE, Javier B, Javier M, Rojas JM: Polymorphisms G691S/S904S of RET as genetic modifiers of MEN 2A. Cancer Res 2003;63:1814-1817.

28 Rossella E, Barbara C, Cristina R, Valeria B, Mariangela S, Riccardo L, Roberto B, Furio P, Aldo P: RET exon 11 (G691S) polymorphism is significantly more frequent in sporadic medullary thyroid carcinoma than in the general population. J Clin Endocrinol Metab 2004;89:3579-3584.

29 Rotondi M, Ercolino T, Fonte R, Lagonigro MS, Leporati P, Villani L, Manna LL, Mannelli M, Chiovato L: Occurrence of medullary thyroid carcinoma, bronchial carcinoid tumor, and papillary thyroid carcinoma in a family bearing the RET G691S polymorphism. J Endocrinol Invest 2009;32:115-118.

30 Shifrin AL, Ogilvie JB, Stang MT, Fay AM, Kuo YH, Matulewicz T, Xenachis CZ, Vernick JJ: Single nucleotide polymorphisms act as modifiers and correlate with the development of medullary and simultaneous medullary/papillary thyroid carcinomas in 2 large, non-related families with the RET V804M proto-oncogene mutation. Surgery 2010;148:1274-1281.

31 Shun SC: Cancer Prehabilitation for patients starting from active treatment to surveillance. Asia Pac J Oncol Nurs 2016;3:37-40. 


\section{Erratum}

In the article by Zhang et al., entitled "Rare RET Variant p.D707E in a Chinese Pedigree with Hereditary Medullary Thyroid Carcinoma" [Pathobiology DOI: 10.1159/000448845], the author "Dai Wang" with the affiliation "a" was missing in the original publication. The correct authorship is as follows:

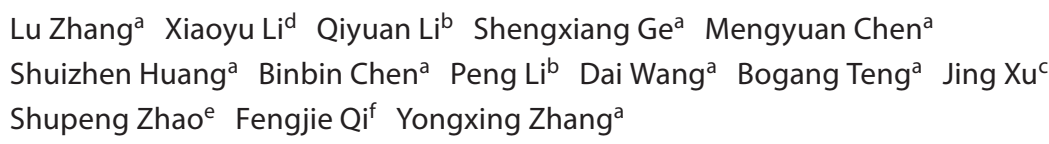

a State Key Laboratory of Molecular Vaccinology and Molecular Diagnostics, School of Public Health, and ${ }^{b}$ School of Medicine, Xiamen University, Xiamen, Departments of ${ }^{\mathrm{C}}$ Gynecology and ${ }^{\mathrm{d}}$ Otolaryngology-Head and Neck Surgery, The Affiliated Hospital of Jining Medical University, Jining, and Departments of ${ }^{\mathrm{e}}$ Thyroid and Breast Surgery and ${ }^{\mathrm{f}}$ Pathology, Luohu People's Hospital, Shenzhen, PR China

Moreover the acknowledgement was incomplete and must be as follows:

\section{Acknowledgement}

This study was financially supported by a grant from the Shandong Provincial Medical and Health Science and Technology Development Plan (2014WS0197) and NSFC grant No. 81301474. 